\title{
Subacute spongiform encephalopathy and its relation to Jakob-Creutzfeldt disease : report on six cases
}

\author{
Y. GOLDHAMMER, J. J. BUBIS, IDA SAROVA-PINHAS, AND J. BRAHAM \\ From the Departments of Neurology, Cell Biology, Histology, and Pathology, \\ Tel-Hashomer Government Hospital, Tel Aviv University Medical School, Israel
}

SUMMARY An account is given of six cases of Jakob-Creutzfeldt disease confirmed at necropsy. The rapid fatal outcome within three months was typical of the variety designated subacute spongiform encephalopathy (Nevin-Jones). The characteristic EEG changes were found to be of great value in making an early diagnosis and, together with akinetic mutism and myoclonus, constituted an easily recognizable picture. Treatment with idoxyuridine was ineffective in one case in which electronmicroscopy of brain biopsy material supported the diagnosis.

Jakob-Creutzfeldt disease, a fatal form of subacute encephalopathy encountered mostly in the middle aged, is generally considered to be a rare disorder. The intriguing nature of the clinical, laboratory, and pathological aspects has led recently to the appearance of extensive reviews (Garcin, Brion, and Khochneviss, 1963; Siedler and Malamud, 1963; Nevin, 1967; May, 1968), a symposium (Guazzi and Seitelberger, 1967), and a monograph (Kirschbaum, 1968), devoted to the subject. None the less, many cases may well continue to be missed through unfamiliarity with the main features; even the pathologist may fail to make the diagnosis because of unawareness that typical histological changes may be only patchily distributed in the central nervous system. We present here the clinical, electroencephalographic, and pathological findings in six cases, which we believe serve to show that the disorder has a well-defined and readily recognizable pattern during life. The importance of making the diagnosis has received considerable impetus following the recent demonstration that the disease is due to a transmissible agent, a discovery which will surely stimulate efforts to devise an effective therapy.

\section{CASE 1}

A.M., a 57 year old street cleaner, two years before his death underwent gastrectomy for peptic ulcer and one year before his present admission had been treated for depression in a mental institution. Improvement had followed treatment with phenothiazine derivatives in a few weeks. However he had been readmitted, a month before transfer to our hospital, in a state of deterioration and neglect. Movements and speech were slow and communication poor. His responses were either in the form of echolalia, or limited to the assertion that his 'head was not working'. He would occasionally smile in a fatuous way. During the next few weeks he became somnolent; there was increasing muscular rigidity and jerking of the limbs. Communication was lost entirely and he became doubly incontinent. On transfer to this department he was found to be cachectic, mute, lying immobile with eyes open. The limbs were in a position of flexor rigidity, and showed marked resistance to passive movement, as did the neck muscles. Frequent myoclonic jerks were noted in the limbs and face and these were considerably augmented by sudden noise and whenever he was touched.

Skull films were normal. The electroencephalogram (EEG) was grossly disturbed, no normal rhythms being seen, while delta and bisynchronous sharp waves appeared in all channels (Fig. 1). The cerebrospinal fluid (CSF) was yellow, under normal pressure, and contained $200 \mathrm{mg}$ protein $/ 100 \mathrm{ml}$. Right carotid angiography with contralateral carotid compression showed a half-centimetre separation of brain from skull. Burr-holes were drilled and confirmed the impression that this picture was due to brain atrophy and not to bilateral subdural haematoma. CSF obtained at the time contained $500 \mathrm{mg}$ protein $/ 100 \mathrm{ml}$. The clinical state remained unchanged until death three weeks after admission. 

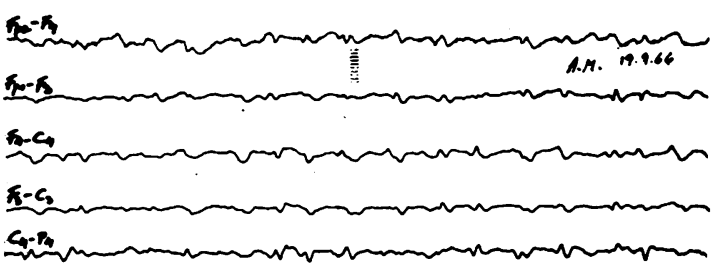

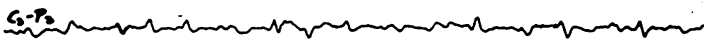

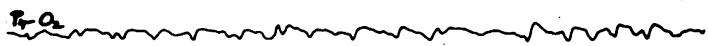

B-O. 0 .

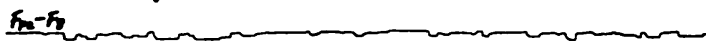

Fon

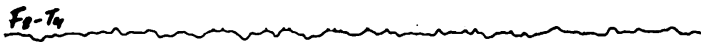

Facts

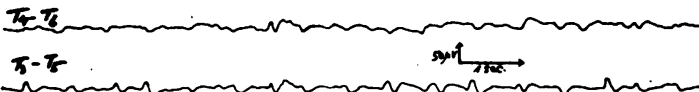

FIG. 1. Case 1. The background is irregular and dysrhythmic with occasional delta waves. 'Triangular' or diphasic sharp waves are seen in all leads, sometimes bisynchronous, sometimes on one side only.

At necropsy the lungs showed severe bronchopneumonia. The brain weighed $1,100 \mathrm{~g}$. The frontal lobe gyri were thinned and the sulci wide. The subarachnoid space was dilated and filled with viscous fluid which spilled out when the dura mater was opened. On microscopy marked changes were seen in the parietal lobes of the brain. The lesions were patchy and localized mainly to the IIIrd to Vth layers of the cortex. Numerous neurones had disappeared; the neuropil seemed rarefied but no obvious spongiosis was seen. There was gliosis with presence of numerous astrocytes, a few of which were of the so-called 'gemistocyte' type. Most showed large vacuolar or pale stained nuclei. The nuclei were mainly rounded or oval. Some had a bizarre or irregular shape. Similar lesions were seen also in the hippocampus. Elsewhere in the central nervous system (CNS) there was no loss of neurones, but gliosis was seen in frontal lobes, lentiform nuclei, and in thalamic and subthalamic regions. Numerous corpora amylacea were seen everywhere in the CNS particularly so in the subependymal region.

\section{CASE 2}

B.P. was a 67 year old male, previously well apart from cholelithiasis necessitating cholecystectomy three years ago. About three weeks before admission he had become irritable and argumentative, complained of headaches and difficulty in concentration, and declared that attempts were being made on his life. In the next few days he became secretive, spoke little, and showed difficulty in comprehension, at which stage he was admitted. Verbal contact was now no longer possible, with no response to commands and little or no spontaneous activity. He had to be fed and soiled his bed. Occasional choreiform movements and myoclonic jerks were observed. Tendon reflexes were brisk, more so on the right with a Babinski sign.

Skull radiography was normal, as were routine blood, urine, and CSF examinations; serological tests for syphilis were negative. However, the EEG showed characteristic changes with absence of normal rhythms, prominent theta activity, and bilaterally synchronous sharp waves at intervals of one half to one second (Fig. 2).

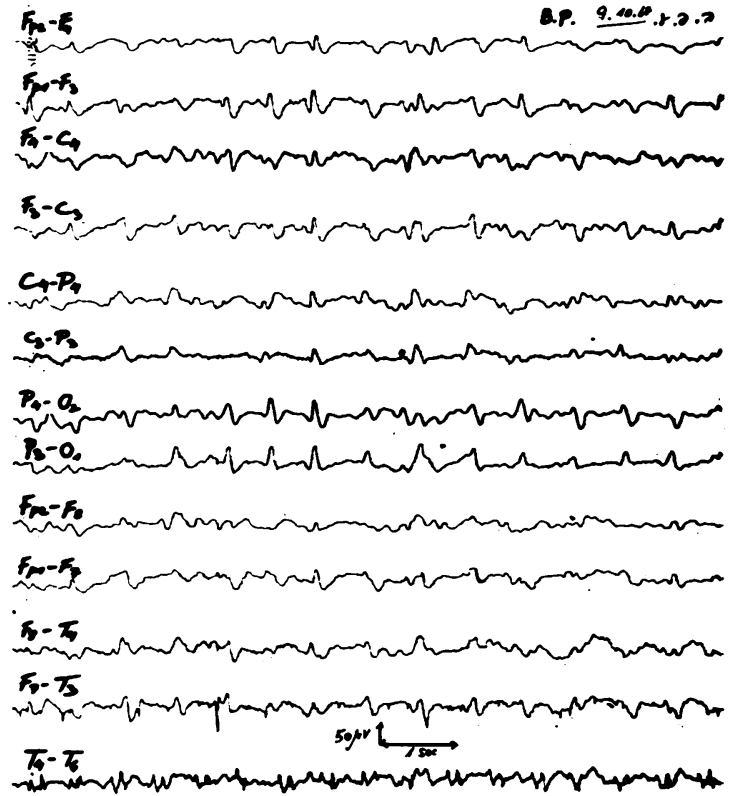

FIG. 2. Case 2. Four weeks after onset of illness. Bilateral repetitive 'triangular' waves or biphasic sharp waves are seen against an irregular background.

Clinical deterioration was rapid with widespread frequent myoclonus and fasciculation. Responses were limited to head turning provoked by noise, or to occasional echolalia. At the same time certain acquired cultural habits were observed, such as putting hand to mouth when coughing. During the next few days he sank into coma in a posture of flexor rigidity. Myoclonus was even more pronounced and was occasionally seen to synchronize with sharp waves in the EEG. The patient died seven weeks after the onset of symptoms.

No gross abnormalities were seen at necropsy. 


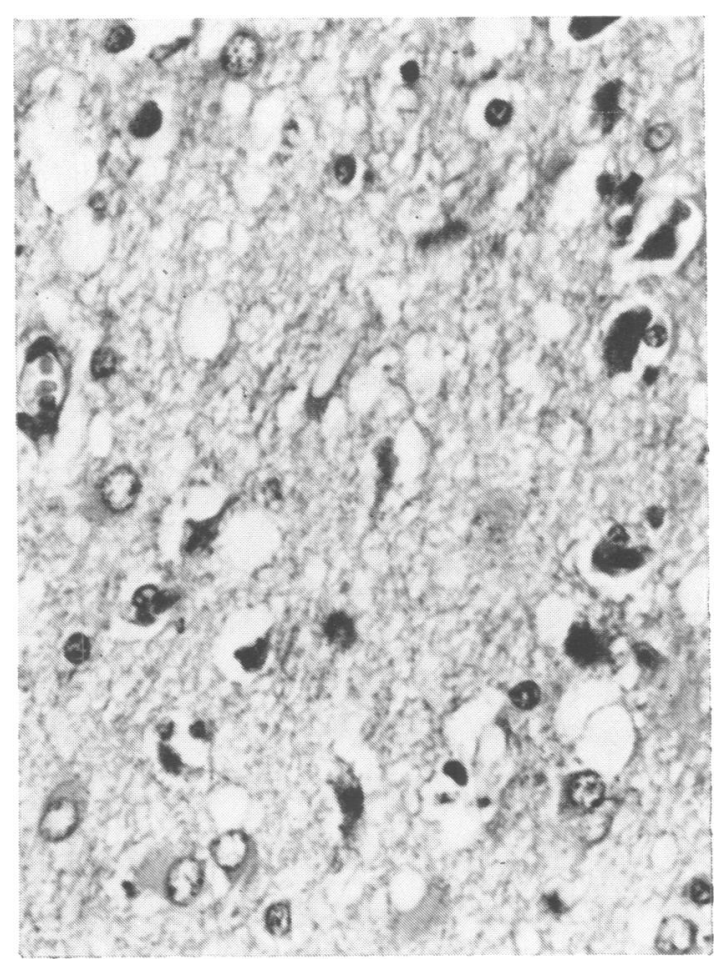

FIG. 3. Case 2. Frontal cortex showing astrocytosis with gemistocytes. The striking feature is the large vacuolated nucleus of the astrocytes. $H$ and $E, \times 350$.
The brain weighed 1,330 g. Sulci and gyri appeared normal as did the cut sections. On microscopy of the brain lesions were seen in the frontal lobes only, and were severe in the frontal pole and in precentral gyri. In these areas the cortex showed depopulation of nerve cells in all layers and neuronophagia. The cortex showed patchy microspongiosis. Astrocytosis was evident throughout the depopulated areas, many of the astrocytes having large vesiculated nuclei and abundant basophilic cytoplasm (Figs 3, 4). Midfrontal lobe sections were normal. A few scattered areas with slight changes were seen in the postcentral gyri. Numerous sections of cerebral cortex, basal ganglia, and brain-stem failed to show any abnormality. Corpora amylacea were few and scattered.

\section{CASE 3}

L.R., a 42 year old female, was the mother of six children. Four weeks before admission she had been given hormone treatment for amenorrhoea. Later she had received a phenothiazine preparation and ergotamine because of complaints of headaches. Alterations in behaviour, apathy, difficulty in walking, and involuntary movements of the head and limbs led to her admission to hospital. By this time communication with the patient was minimal. She walked with great difficulty and was grossly dysarthric. Spasticity and coarse, non-rhythmic shaking of the limbs were noted. These movements became more extensive in the next few days and were compounded of tremor, athetosis, and ballismus. At the same time voluntary purposeful movements ceased entirely. She lay uncommunicative with open eyes and only rarely attentive to her surroundings. Skull

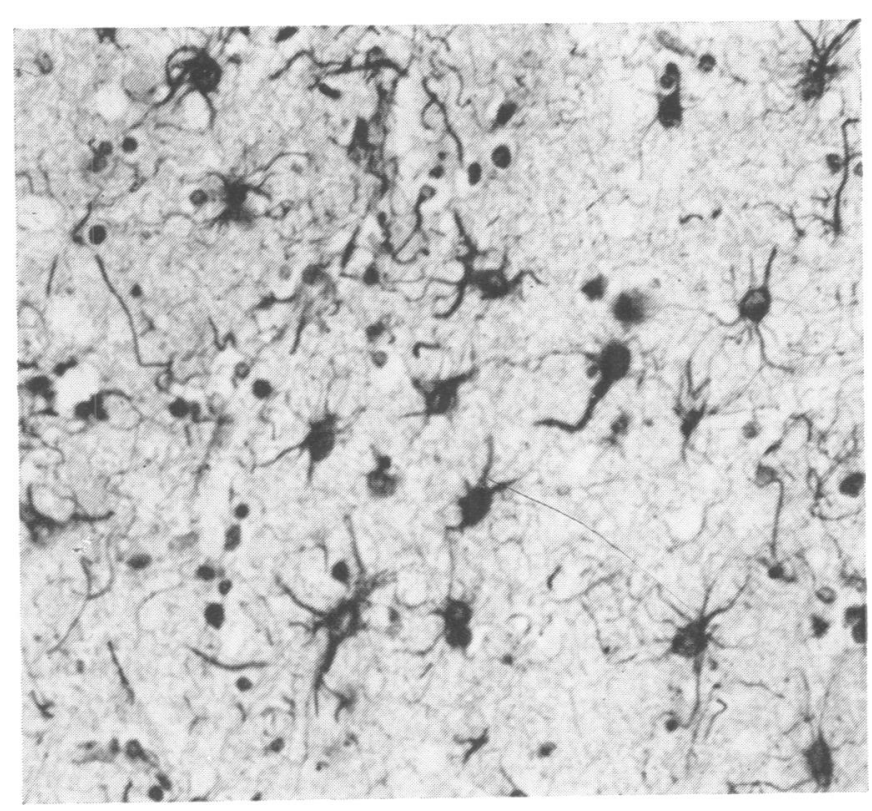

FIG. 4. Case 2. Astrocytosis of the neurone-poor areas in the frontal cortex. Holzer, $\times 400$. 
films, routine laboratory tests, and the CSF were all normal. An EEG examination was not possible because of the involuntary movements. At this stage she was transferred to a psychiatric ward with a diagnosis of acute psychosis, but soon passed into a state of akinetic mutism, refusing to swallow food or fluids; myoclonic jerks appeared and were augmented by physical contact. The EEG examination could now be carried out and showed theta and delta waves superimposed on the background activity, and bisynchronous sharp waves at halfsecond intervals (Fig. 5). Soon after she became comatose and rigid, and died of sepsis three months from the beginning of her illness. In this case

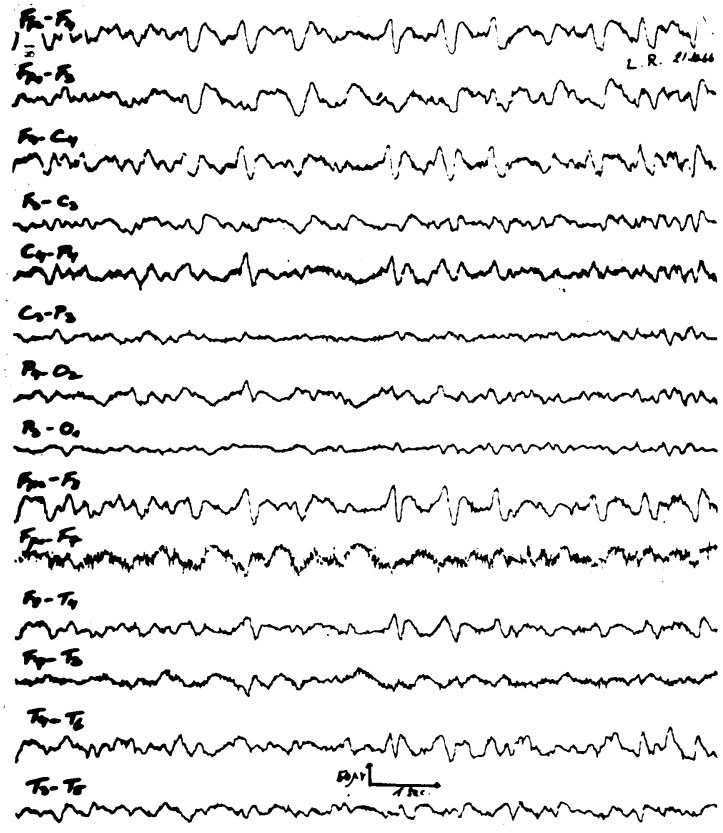

FIG. 5. Case 3. Four weeks after onset of symptoms. High amplitude biphasic sharp waves are seen predominantly from the right hemisphere on a mostly dysrhythmic background.

the correct diagnosis was not made during life. On admission the bizarre movements were interpreted as drug-induced dyskinesia. Later the diagnoses of toxic encephalopathy, acute encephalitis, or psychosis were entertained. The experience of the two previous cases led to a reappraisal of the pathological material and to a correct diagnosis.

At necropsy old caseous lesions of the bodies of L3 and L4 vertebrae and of the intervertebral disc were discovered. No other pathological changes were noted and in particular the blood vessels showed no evidence of arteriosclerosis. Microscopy of the brain showed lesions throughout the cerebral cortex, basal ganglia, and posterior parts of thalamus. The hippocampus, brain-stem, and은 cerebellum were spared. The lesions were severe but ${ }_{\alpha}$ varied in degree from gyri to gyri and even in the same gyrus; there was diffuse spongiosis withos obvious loss of neurones (Fig. 6). Most of the neurones present showed signs of degeneration- 0 namely, shrunken acidophilic cytoplasm and small, dark stained nuclei. Marked gliosis was seen; many? astrocytes had the appearance of gemistocytes (Fig. 7). Other astrocytes showed large vesiculated nuclei.

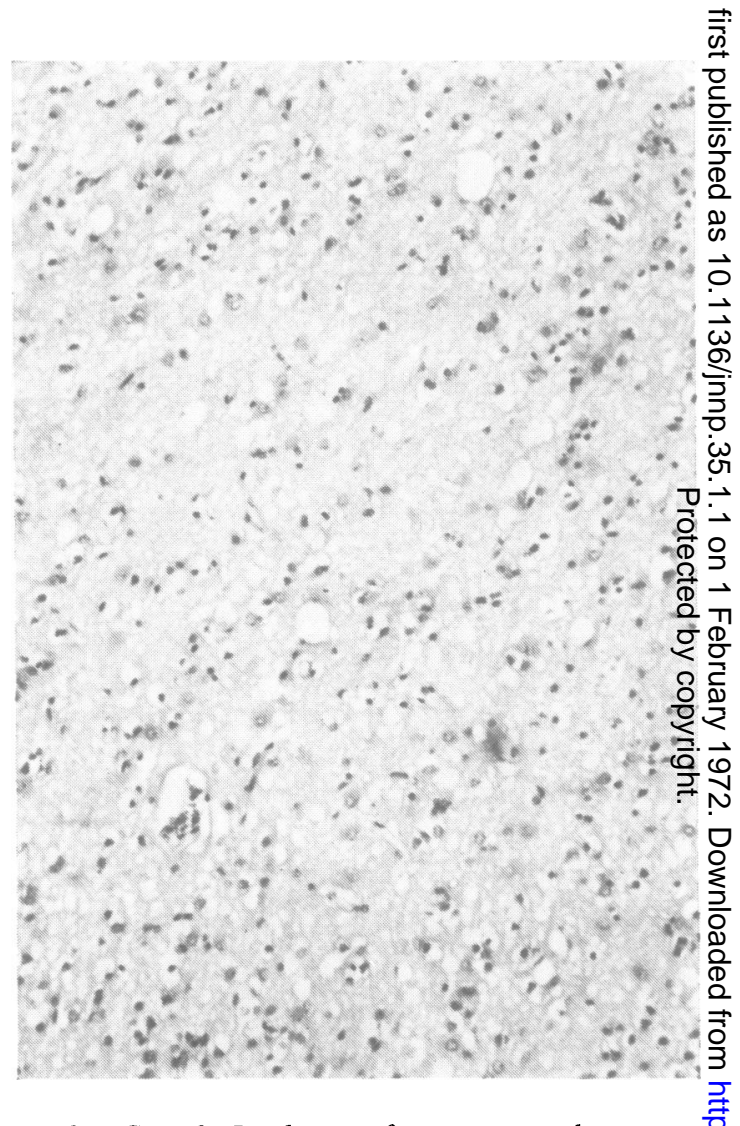

FIG. 6. Case 3. Depletion of neurones in the cortex, microspongiosis and obvious gliosis. $H$ and $E, \times 120$.

and small amount of cytoplasm. The oligodendroglial cells were unaffected.

\section{CASE 4}

A.M., a woman aged 68 years, was admitted to a medical ward because of a two weeks' history of으․ abdominal pain, vomiting, and constipation. Recent mental disturbances including episodes of confusion and some difficulty in walking were also reported. $N$ Investigations directed to the abdominal symptoms N were unrewarding. The EEG, carried out because of the personality changes, showed a background of 


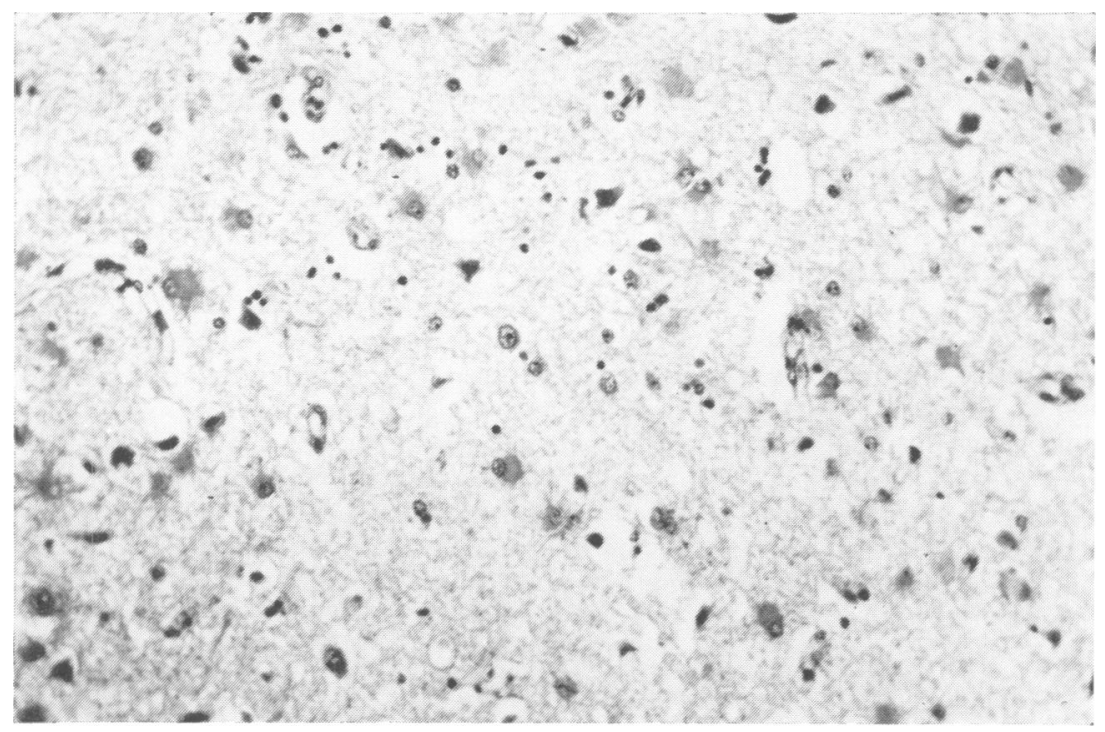

FIG. 7. Case 3. Cortex. Surviving neurones in the upper part of the picture show shrinkage. Astrocytosis with gemistocytes. $H$ and $E$, $\times 200$.

alpha rhythms but, in addition, theta activity especially in the parietal regions. Furthermore bilateral sharp-waves were seen every few seconds. The findings were interpreted as being indicative of Jakob-Creutzfeldt disease. After a major fit the patient was transferred to this department. Spontaneous movements were rarely evident and speech was limited to an occasional response; she was mostly unreactive to verbal commands. Myoclonic contractions, noted chiefly in the legs, were intensified whenever she was touched. Muscular tone was increased with a left Babinski sign. Retention of urine necessitated catheterization. Repeat EEG showed diminution of alpha and increased theta activity; bisynchronous sharp waves recurred every half to one second (Fig. 8). After further major fits phenytoin treatment was begun. Contact with the patient was progressively lost until coma supervened. She died in a state of febrile dyspnoea two months after the first appearance of symptoms.

Post-mortem examination was limited to the brain, which showed no external pathological features. On microscopy, the changes were patchy and localized mainly to the cortex of the posterior areas of the frontal and parietal lobes and thalamus. The findings were characterized by partial loss of neurones, more marked in the superficial layers of the cortex. Now and then neurones were shrunken with small darkly stained nuclei. The cortical areas showed microspongiosis, but this was not obvious in the thalami. Astrocytosis was present in the abovementioned areas, with the characteristics of gemistocytes having large, oval, and lightly stained nuclei. Others showed large nuclei with scanty cytoplasm and few processes. These changes were asymmetrical, the right parietal and temporal lobes showing severe lesions, the left side being only slightly affected.
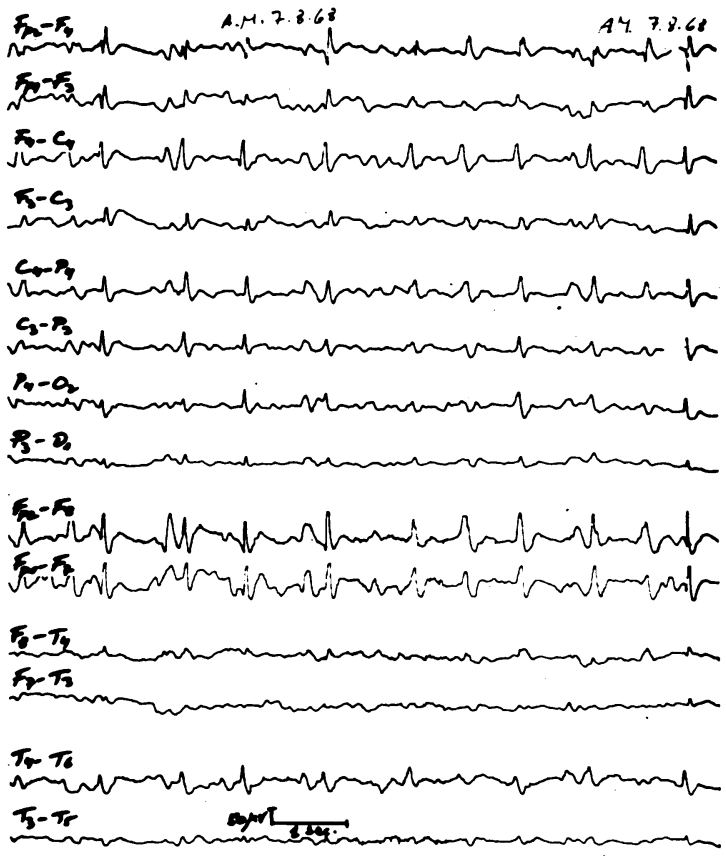

FIG. 8. Case 4. EEG five weeks before death, showing high amplitude bilaterally synchronous sharp waves on a background of theta and occasional delta activity.

\section{CASE 5}

G.S., a 79 year old woman, suffered two strokes with left hemiparesis 18 months and one year before admission respectively. These led to hospitalization in a chronic disease institution because of an organic 
mental syndrome. Diabetes mellitus was discovered and treated with chlorpropamide. Because of progressive clouding of consciousness and fever during the previous few days, she was transferred to this hospital suspected of having suffered yet another stroke. She was found to be uncooperative, but reacted to her name being called. The limbs were hypertonic and tendon reflexes brisk, but plantar responses were not obtained.

Mild hypoglycaemia ( 88 to $64 \mathrm{mg} / 100 \mathrm{ml}$. blood sugar) persisted for a few days in spite of glucose infusions. The fever responded to appropriate therapy but her general condition did not improve. She lay immobile and failed to respond even when a fly crawled over her open eyes. An EEG record taken 12 days after admission showed a background of theta and delta activity and repetitive sharp waves every half to one second in the anterior and central leads. Progressive obtundation was followed by death 18 days after admission.

The general post-mortem findings were those of severe generalized and cerebral arteriosclerosis with old myocardial infarcts. The brain weighed $1,200 \mathrm{~g}$ and showed no gross external evidence of disease.

On microscopy of the brain, arteriosclerotic changes were obvious and marked in all slides examined. Medium and small arteries in brain and arachnoid matter had thickened intima and medial layers. Here and there the arterial lumen was narrowed. Changes in grey matter were patchy and varied in intensity from area to area, and in many areas this difference was seen even in the same low power field. The striking features were disappearance of neurones with associated gliosis made up of protoplasmic astrocytes, many of them having large vacuolated nuclei. In the anterior part of frontal lobes microspongiosis of first layers was present with relatively well-preserved deeper layers. The astrocytic proliferation was mostly of the large vacuolated nuclei type. Patchy areas of disappearance of neurones were seen side by side with well-preserved cortex. Similar areas of neuronal loss and astrocytic proliferation with small dark nuclei were seen in the heads of the caudate nuclei, adjacent to the lateral ventricles.

\section{CASE 6}

B.C., a 63 year old man, 10 months before admission suffered a head injury without loss of consciousness. He stopped work a month before hospitalization because of difficulty in walking, headaches, and giddiness. Gait was spastic, ataxic, and wide based, with an unstable stance. There was weakness of the left limbs, choreiform movements of the left arm, generalized hyperreflexia, and doubtful plantar responses. Finger-nose and heel-knee tests were poorly performed and speech was dysarthric.

Skull radiographs were normal, but pneumoencephalography revealed considerable cortical atrophy with normal sized ventricles. The CSF contained 5 lymphocytes/cu.mm and protein $30 \mathrm{mg} /$ $100 \mathrm{ml}$. Blood and urinalysis were normal. EEG findings showed a characteristic pattern of recurring sharp waves (Fig. 9a). His condition declined rapidly on during the next three weeks. Increasing ataxia rendered him bed-ridden, while the choreiform 0 movements on the left became more marked. He $\stackrel{\infty}{\sim}$ became confused and myoclonic jerks appeared. Repeat EEGs showed progressive augmentation of pathological features (Fig. 9b-c). Simultaneous EEG $?$ and EMG recordings showed synchronization of $\vec{F}$ sharp waves and myoclonic contractions (Fig. 9d). Material from brain biopsy of the right parietal area revealed no abnormalities on light microscopy but electron microscopy of the specimen showed spongiosis and gliosis. A course of idoxyuridine, $15 \mathrm{~g}$ over 5 days, was given intravenously. This had के no appreciable effect on his condition which continued to deteriorate. Immobility was complete except for myoclonus. There were several major epileptic fits. Death took place six weeks after admission.

At necropsy, bronchopneumonia of the right lung with pleural adhesions was noted. The brain was of grossly normal except for the local changes produced. by the cortical biopsy. Histological examinatio showed diffuse pathological changes in various area of the cortex, thalamus, hypothalamus, and basa ganglia though most marked in the parietal an $\mathbb{D}$ occipital lobes. All layers of the cerebellum in numerous sections appeared normal. The corte showed astrocytosis everywhere more marked in the deeper layers. Many of the pathological astrocyte possessed a large vesicular nucleus. In the regions most affected the astrocytes were aggregated in the middle layers in small clumps where neurones had disappeared. In those areas microspongiosis was present, particularly in the occipital lobes.

\section{DISCUSSION}

The original descriptions refer only to one case (Creutzfeldt, 1920) and five cases (Jakob, 1921), so that, as is often the situation with eponymous syndromes, confusion arises as to what may be 'legitimately' included under the heading JakobCreutzfeldt disease. Attempts at classification with up to six sub-groups have been based on various combinations of length of history and the presence or absence of individual clinical or pathological features (Garcin et $\frac{T}{O}$ al., 1963; Siedler and Malamud, 1963; Nevin, 1967; Kirschbaum, 1968; May, 1968). A well- م defined group of cases, characterized by a short $N$ history with a fatal outcome in weeks or months $\underset{\mathrm{N}}{\mathrm{N}}$ and a recognizable EEG pattern has been separated by Jones and Nevin (1954) and 0 


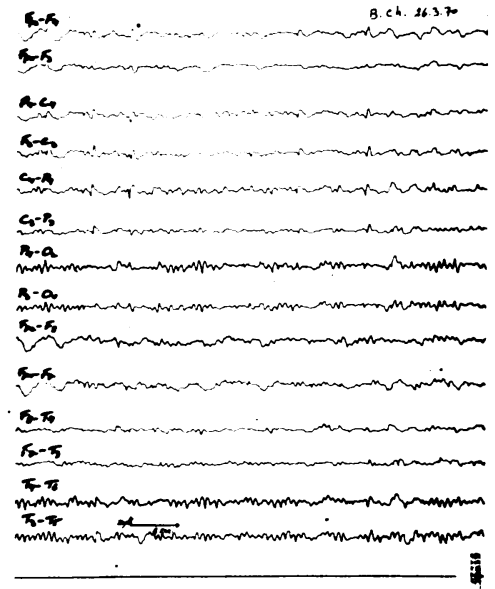

(a)

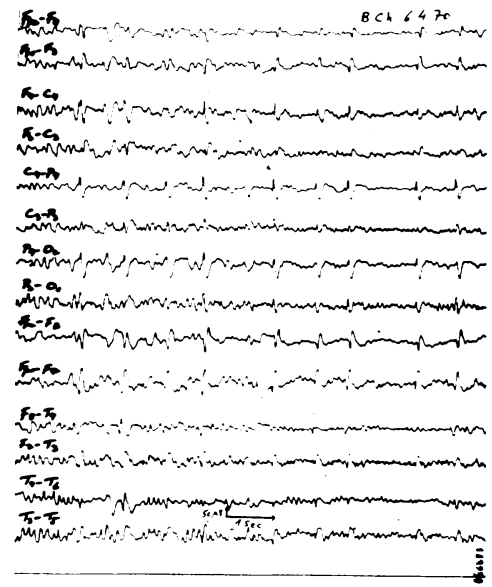

(b)

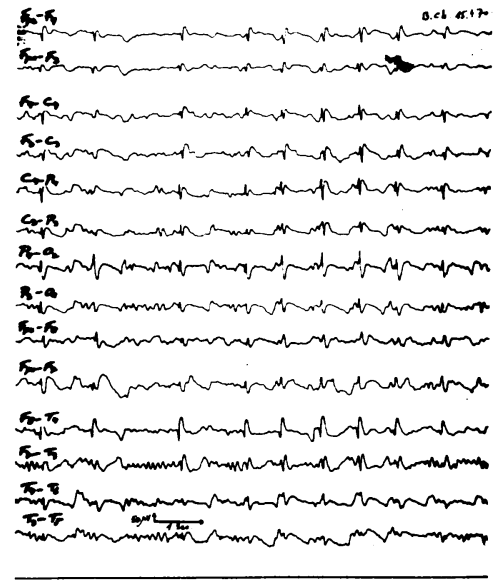

(c)

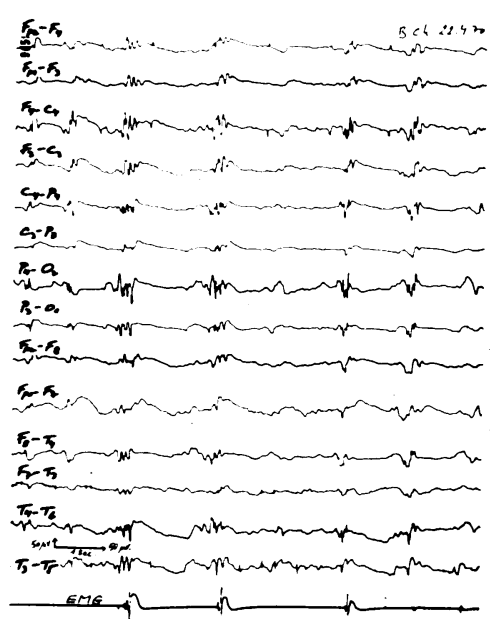

(d)

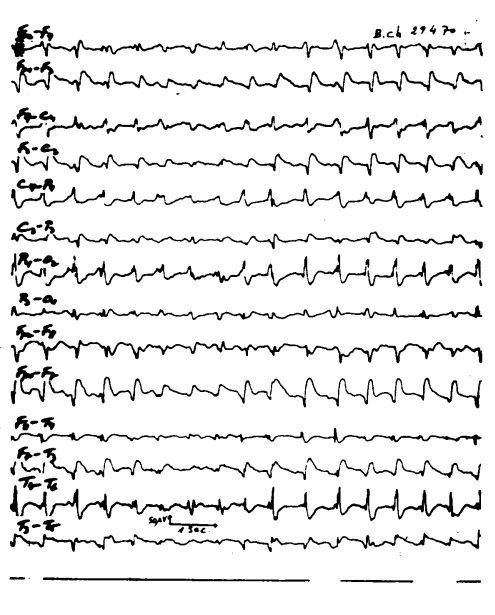

(e)
FIG. 9a-e. Case 6. Shows the evolution of EEG changes over a period of five weeks. In Fig. 9a a stable occipital alpha rhythm is evident and still recognizable in Fig. 9c three weeks later. Meanwhile, the repetitive spike pattern has begun to dominate the picture. Figure 9d: EMG recording in the last channel shows synchrony of myoclonic jerks with bursts of polyspikes in the EEG.
McMenemey and Nevin (1955) and designated 'subacute spongiform encephalopathy' (SSE) (Nevin, McMenemey, Behrman, and Jones, 1960). Of 102 cases reviewed by Nevin (1967) 60 could be classified in this way, including some with cortical blindness (Heidenhain syndrome). The six cases reported above all fall into this special category of SSE, and their various features are summarized as follows.

\section{CLINICAL ASPECTS}

The ages of our patients ranged from 42 to 79 years. Only one other case at the latter extreme age has been reported in the literature (Verhaart, 1927). The sex ratio was $1: 1$; two were Ashken- azi Jews and of the other four, three were immigrants from Libya. In another series of six cases reported from this country (Behar, Sroka, Elian, Kott, Korczyn, Bornstein, and Sandbank, 1969) two were Libyan immigrants, so that the total incidence of five out of 12 of Libyan origin is of some interest. It is not known whether these patients were related.

The symptomatology and march of events were similar in all cases. After an initial phase characterized by complaints of general weakness, headache, difficulty in concentrating or emotional disturbances, signs of dementia rapidly supervened with confusion and speech difficulties going on to mutism. At this stage, involuntary movements and myoclonus made their appearance. Mental disturbances dominated 
the picture from the onset in five patients. One (case 6) presented with an apparent cerebellar syndrome. We failed to find histological changes in the cerebellum in this case, although these have been reported in this sub-group by Brownell and Oppenheimer (1965). The 'cerebellar' symptoms could therefore possibly have been due to frontal lobe disease. Abdominal pains were complained of in another (case 4). Increased muscular tone was noted in all patients and various signs of pyramidal tract lesion in four. In the final stages all showed akinetic mutism, with flexor rigidity in three. Myoclonic jerks made worse by contact or noise were present in five. Major fits occurred in two patients. All died within three months of the onset of progressive symptoms; the significance of the depressive illness one year previously in case 1 is not clear.

\section{EEG CHANGES}

May (1968) reviewing the EEG findings in 68 cases from the literature, concludes that they may vary during the course of the illness. The EEG may be normal even in the presence of neurological abnormalities but usually there are diffuse or focal changes as the disease progresses with the final emergence of the characteristic burst pattern. In all our patients the EEG was abnormal. The records showed the characteristic disturbances described by Nevin and Jones (1954) - namely, absence of normal background rhythms, the appearance of high-voltage slow activity and, most striking, repetitive bisynchronous single mono- or biphasic sharp waves. These latter, recurring every half to two seconds have a superficial resemblance to an electrocardiographic artefact. In cases 2 and 6 the simultaneous relationship of sharp waves to myoclonic jerks could be demonstrated as described among others by Christensen and Brun (1963), and Nevin (1967). When recorded in adult patients with the type of clinical history described above, this EEG pattern may be regarded as pathognomonic. In four of our own six cases, the diagnosis was made in the first instance on the basis of the EEG findings. Nevin asserts that the pattern is characteristic of his subacute spongiform encephalopathy group only. Pallis and Spillane (1957) saw it in no other condition in 8,600 examinations. Katzman, Kagan, and Zimmerman (1961) refer to the diagnostic triad of akinetic mutism, myoclonus, and specific EEG changes. However, the EEG picture appeared early in the disease in three of our cases before akinetic mutism and myoclonus, at a time when dementia was the presenting symptom. Experience with the first two patients did indeed enable our EEG technician to suggest the correct diagnosis in the remaining four.

\section{PATHOLOGICAL FEATURES}

Macroscopically the brain in this disorder appears normal or somewhat atrophic. The $\overrightarrow{\overline{\vec{S}}}$ histological changes found in grey matter are $\overrightarrow{0}$ summarized as the triad of loss of neurones, astrocytosis, and status spongiosus. Seen principally in the cortex, they may be present to some extent in thalamus and striatum. Nevin et al. (1960), with regard to the group of cases referred to by them as SSE, base their attitude also on detailed pathological differences characteristic of this particular variety. These include a specia form of neuronal degeneration and marked status spongiosus with predilection for the occipital lobes and sparing of the brain-stem and spinal cord. Many of their cases showed patho logical features in the cerebral vessels, and th resulting ischaemia is proposed as the essentia $\vec{B}$ aetiological factor. However, most pathologistQ who discuss this problem take a 'unitary viewo as opposed to the 'dualistic' school (Siedler an Malamud, 1963; Lafon, Labauge, Bogaert, and $\overrightarrow{0}$ Castan, 1965; Brion, 1967; Coërs, Castan, va Reeth, and Péner, 1967; Capon, Flament, and Guazzi, 1967; Jacob and Bogaert, 1967; Kirschbaum, 1968). They maintain that there is a wide range in degree and extent of the pathological changes, and that this diversity is also found in an overlapping way in the various clinical forms, not excluding SSE. Even status spongiosus is not a sine qua non for the diagnosis of SSE. In our own cases it was present but not marked. Jacob and Bogaert (1967), Macchi and Lechi (1967), Terzian, Rizzuto, Patarnello, and Martin (1967) have emphasized that pathological findings may be so scanty that a sub group of 'anatomo-clinical dissociation' has been referred to. In our own case 2 , for example, it was necessary to examine many sections before typical histological abnormalities were seen, and these were often so circumscribed that they could be observed side by side with areas of normal tissue. Had a firm clinical diagnosis not warranted intensive re-examination, the histological changes could well have been missed. Again in case 6 , biopsy of the brain was regarded as 
negative by light microscopy, whereas electronmicroscopy confirmed the diagnosis. Cases have been reported with absence of acetylcholinesterase and monoamine oxidase as the sole manifestation of disease in some areas appearing normal on microscopy (Robinson, 1969). Our feeling is that clinical and EEG findings taken together are crucial and that in any one case insistence on all elements of the histological manifestations is unnecessary.

In the matter of pathogenesis there is no unity of opinion as to whether astrocytosis leading to loss of neurones is primary, or whether the reverse order of events obtains. Electronmicroscopy has, however, clarified the stages of development of the spongiosis. This begins with widenings of the vesicles of the endoplasmic reticulum of the astrocytary processes which by fusion form the vacuoles of the 'sponge' (Foncin, 1967; Kidd, 1967; Sluga and Seitelberger, 1967).

\section{AETIOLOGY}

The unsatisfactory conception of 'degenerative disease' hitherto postulated seemed ill-adapted to a disease sometimes fatal in a matter of weeks. On the other hand, it was agreed that the usual histopathological concomitants of an acute virus encephalitis were also lacking. However an analogous situation in the disease 'kuru', an unusual encephalopathy occurring in New Guinea, was resolved when Gajdusek, Gibbs, and Alpers $(1966,1967)$ showed by successful passages in monkeys, that this latter disorder belonged to the group of slow virus infections. Similarly this group of investigators demonstrated in 1968 that a transmissible agent could be implicated in Jakob-Creutzfeldt disease (Gibbs, Gajdusek, Asher, Alpers, Beck, Daniel, and Matthews, 1968). So far four chimpanzees have been infected by intracerebral inoculation of biopsy material from four patients. After 12 to 14 months, the animals presented a similar clinical syndrome and appropriate pathological changes (Gibbs and Gajdusek, 1969) with successful passage from monkey to monkey (Beck, Daniel, Matthews, Stevens, Alpers, Asher, Gajdusek, and Gibbs, 1969). Meanwhile Vernon, Horta-Barbosa, Fuccillo, Sever, Baringer, and Birnbaum (1970) have reported electronmicroscopic illustration of virus-like particles in affected brains. Although these authors do not distinguish between various forms of Jakob-
Creutzfeldt disease, the detailed clinical histories of two of the patients from whose brains material was taken for inoculation seem to be typical of the subacute spongiform encephalopathy variety. Evidence for virus transmission of the 'classical' form of the disease has not yet been presented, so that decisive laboratory confirmation of the unitary view point is still lacking.

An ischaemic aetiology proposed by Nevin has found few supporters and indeed the slight vascular changes sometimes found seem inadequate to account for the rapid and malignant evolution of the disease. However, ischaemic episodes, and other potential insults including head injuries, anaesthesia, and hypoglycaemia, could conceivably provoke activity in a dormant virus present in the CNS. Nevin (1967) and Kirschbaum (1968) mention these factors as possibly being relevant. Of our own patients, two underwent laparotomy under general anaesthesia two years before onset of the disease, one suffered a stroke a year previously, and another a head injury 10 months before his final illness.

\section{TREATMENT}

Although there are no records of successful therapy of slow virus infections in man and it is as yet not known whether a DNA or RNA agent is responsible in this disease, the hopeless prognosis was thought to justify a trial of idoxyuridine. Similar considerations have prompted others to essay this or similar preparations in amyotrophic lateral sclerosis (Liversedge, Swinburn, and Yuill, 1970) and subacute sclerosing panencephalitis (Freeman, 1969). A comparable lack of success has attended all these efforts.

\section{REFERENCES}

Beck, E., Daniel, P. M., Matthews, W. B., Stevens, D. L., Alpers, M. P., Asher, D. M., Gajdusek, D. C., and Gibbs, C. J. Jr. (1969). Creutzfeldt-Jakob disease. The neuropathology of a transmission experiment. Brain, 92, 699716.

Behar, M., Sroka, C., Elian, M., Kott, E., Korczyn, A., Bornstein, B., and Sandbank, U. (1969). CreutzfeldtJakob disease and its relation to pre-senile dementia. Harefuah, 77, 275-279.

Brion, S. (1967). Encéphalopathie spongieuse de la présénilité et syndrome de Creutzfeldt-Jakob. In: Symposium on presenile spongy encephalopathies, Venice, 1965. Acta Neuropathologica, Suppl. 3, 16-21.

Brownell, B., and Oppenheimer, D. R. (1965). An ataxic form of subacute presenile polioencephalopathy (CreutzfeldtJakob disease). Journal of Neurology, Neurosurgery, and Psychiatry, 28, 350-361.

Capon, A., Flament, J., and Guazzi, G. C. (1967). Le rôle de la barrière hémato-encéphalique dans la maladie de 
Creutzfeldt-Jakob-Heidenhain-Nevin. In: Symposium on presenile spongy encephalopathies, Venice, 1965. Acta Neuropathologica, Suppl. 3, 47-53.

Christensen, E., and Brun, A. (1963). Subacute spongiform encephalopathy. Spongiform cerebral atrophy. Neurology (Minneap.), 13, 455-463.

Coërs, Chr., Castan, Ph., Van Reeth, P. Ch., and Périer, O. (1967). Étude anatomo-clinique d'un cas de maladie de Creutzfeldt-Jakob, varieté d'Heidenhain. In: Symposium on presenile spongy encephalopathies, Venice, 1965. Acta Neuropathologica, Suppl. 3, 42-46.

Creutzfeldt, H. G. (1920). Über eine eigenartige herdförmige Erkrankung des Zentralnervensystems. Zeitschrift für die gesamte Neurologie und Psychiatrie, 57, 1-18.

Foncin, J. F. (1967). Étude ultrastructurale de la maladie de Creutzfeldt-Jakob. In: Symposium on presenile spongy encephalopathies, Venice, 1965. Acta Neuropathologica, Suppl. 3, 127-130.

Freeman, J. M. (1969). Treatment of Dawson's encephalitis with 5-Bromo-2'-deoxyuridine. Double-blind study. $\mathrm{Ar}$ chives of Neurology, 21, 431-434.

Gajdusek, D. C., Gibbs, C. J., Jr., and Alpers, M. (1966). Experimental transmission of a kuru-like syndrome to chimpanzees. Nature, 209, 794-796.

Gajdusek, D. C., Gibbs, C. J. Jr., and Alpers, M. (1967). Transmission and passage of experimental 'kuru' to chimpanzees. Science, 155, 212-214.

Garcin, R., Brion, S., and Khochneviss, A.-A. (1963). Le syndrome de Creutzfeldt-Jakob et les syndromes corticostriés du présénium (à l'occasion de 5 observations anatomo-cliniques). Revue Neurologique, 109, 419-441.

Gibbs, C. J. Jr., Gajdusek, D. C., Asher, D. M., Alpers, M. P., Beck, E., Daniel, P. M., and Matthews, W. B. (1968). Creutzfeldt-Jakob disease (spongiform encephalopathy): transmission to the chimpanzee. Science, 161388 389.

Gibbs, C. J. Jr., and Gajdusek, D. C. (1969). Infection as the etiology of spongiform encephalopathy (CreutzfeldtJakob disease). Science, 165, 1023-1025.

Guazzi, G. L., and Seitelberger, F., eds. (1967). Symposium on presenile spongy encephalopathies, Venice, 1965. Acta Neuropathologica, Suppl. 3.

Jakob, A. (1921). Über eigenartige Erkrankungen des Zentralnervensystems mit bemerkenswertem anatomischen Befunde. (Spastische Pseudosklerose-Encephalomyelopathie mit disseminierten Degenerationsherden.) Zeitschrift für die gesamte Neurologie und Psychiatrie, 64, 147 228.

Jacob, H. and Bogaert, L. van (1967). Synthèse des apports histopathologiques. In: Symposium on presenile spongy encephalopathies, Venice, 1965. Acta Neuropathologica, Suppl. 3, 148-151.

Jones, D. P., and Nevin, S. (1954). Rapidly progressive cerebral degeneration (subacute vascular encephalopathy) with mental disorder, focal disturbances, and myoclonic epilepsy. Journal of Neurology, Neurosurgery, and Psychiatry, 17, 148-159.

Katzman, R., Kagan, E. H., and Zimmerman, H. M. (1961). A case of Jakob-Creutzfeldt disease. 1. Clinicopathological analysis. Journal of Neuropathology and Experimental Neurology, 20, 78-94.
Kidd, M. (1967). Some electron microscopical observations on status spongiosus. In: Symposium on presenile spongy encephalopathies, Venice, 1965. Acta Neuropathologica, Z Suppl. 3, 137-144.

Kirschbaum, W. R. (1968). Jakob-Creutzfeldt Disease. Elsevier: Amsterdam.

Lafon, R., Labauge, R., Bogaert, L. van, and Castan, Ph. (1965). Sur l'unité histopathologique des encéphalopathies subaiguës (Types Creutzfeldt-Jakob, Heidenhain et To Nevin). Revue Neurologique, 112, 201-227.

Liversedge, L. A., Swinburn, W. R., and Yuill, G. M. (1970). ำ Idoxuridine and motor neurone disease. British Medical Journal, 1, 755-756.

Macchi, G., and Lechi, A. (1967). L'état spongieux dans le diagnostic histopathologique des encéphalopathies du présénium. In: Symposium on presenile spongy encephalopathies, Venice, 1965. Acta Neuropathologica, Suppl. 3, 으 54-55.

McMenemey, W. H., and Nevin, S. (1955). Subacute cerebral $\overline{\bar{\omega}}$ degeneration in myoclonic epilepsy. Excerpta Medica, Section VIII, 8, 780-782.

May, W. W. (1968). Creutzfeldt-Jakob disease. 1. Survey of the literature and clinical diagnosis. Acta Neurologica Scandinavica, 44, 1-32.

Nevin, S. (1967). On some aspects of cerebral degeneration in $\overrightarrow{\vec{A}}$ later life. Proceedings of the Royal Society of Medicine, 60, $\vec{\omega}$ 517-526.

Nevin, S., McMenemey, W. H., Behrman, S., and Jones, D. P. (1960). Subacute spongiform encephalopathy-a subacute form of encephalopathy attributable to vascular $\omega$ dysfunction (spongiform cerebral atrophy). Brain, 83, 519_ o 564.

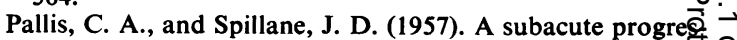
sive encephalopathy with mutism, hypokinesia, rigidit\$ and myoclonus. A clinical and pathological account three cases. Quarterly Journal of Medicine, 26, 349-373. @ T

Robinson, N. (1969). Creutzfeldt-Jakob's disease. A hist $\bar{Q} \mathbb{O}$ chemical study. Brain, 92, 581-588.

Siedler, H., and Malamud, N. (1963). Creutzfeldt-Jakob@ disease. Clinicopathologic report of 15 cases and review the literature (with special reference to a related disorder designated as subacute spongiform encephalopathy Journal of Neuropathology and Experimental Neurology, 22, 381-402.

Sluga, E., and Seitelberger, F. (1967). Beitrag zur spongiösen Encephalopathie. In: Symposium on presenile spongy encephalopathies, Venice, 1965. Acta Neuropathologica, Suppl. 3, 60-72.

Terzian, H., Rizzuto, N., Patarnello, L., and Martin, J. J. (1967). Sur une forme particulière de la maladie de Cruetzfeldt-Jakob, avec dissociation anatomo-clinique. In: Symposium on presenile spongy encephalopathies, Venice, 1965. Acta Neuropathologica, Suppl. 3, 37-41.

Verhaart, W. J. C. (1927). Een eigenaardig geval van spatischepseudosclerose (Jakob). Psychiatrische en Neurologische Bladen, 31, 346-354.

Vernon, M. L., Horta-Barbosa, L., Fuccillo, D. A., Sever, J. L., Baringer, J. R., and Birnbaum, G. (1970). Virus-like particles and nucleoprotein-type filaments in brain tissue from two patients with Creutzfeldt-Jakob disease. Lancet, 1, 964-967.

\section{Addendum}

Since submission of this article for publication, there has been a report from this institution (Braham, 1971) of a further case of this disorder, diagnosed on clinical and electroencephalographic grounds, in which there was an encouraging response to amantadine therapy (Braham, J. (1971). JakobCreutzfeldt disease: treatment by amantadine. British Medical Journal, 4, 212-213.) 